\title{
Analisis Biaya Standar Sebagai Alat Pengendalian Biaya Tenaga Kerja Langsung pada PT Masaiki Jakarta
}

\author{
Rani Suryani', Dwi Budi Srisulistiowati2,* \\ ${ }^{1}$ Fakultas Teknik dan Informatika, Universitas Bina Sarana Informatika, Jl Kaliabang \\ Tengah, Perwira, Kec.Bekasi Utara, Kota Bekasi, Jawa Barat 17124, rani.rsy@bsi.ac.id \\ ${ }^{2}$ Fakultas IImu Komputer, Universitas Bhayangkara Jakarta Raya, Jl.Perjuangan No.81, \\ Marga Mulya, Kec.Bekasi Utara, Kota Bekasi, Jawa Barat 17143, \\ dwibudi@dsn.ubharajaya.ac.id \\ *Korespondensi: e-mail: dwibudi@dsn.ubharajaya.ac.id
}

Diterima: 23 Juni 2021; Review: 26 Juni 2021; Disetujui: 29 Juni 2021; Diterbitkan: 30 Juni 2021

\begin{abstract}
Setting wage rate standards based on the company's ability or agreement between employees and the company as well as the average wages of employees in the past, Efficiency standards are set by looking at the actual performance of a worker. The research method used in this research is descriptive with quantitative approach. The research data used in this study is secondary data. Data sources that do not directly provide data to data collectors, The difference in direct labor costs that occur in PT Masaiki is profitable. Although the difference in profitability in direct labor cost control is not necessarily an optimal profitable difference, but if the company uses standard costs with continuous / continuous analysis of differences in direct labor cost control then the direct labor costs that must be incurred by the company will be low and low costs will increase the profit so that optimal profit will be achieved by the company.
\end{abstract}

Keywords: Direct Labor, Control, Standard Cost

\begin{abstract}
Abstrak
Penetapan standar tarif upah berdasarkan kemampuan perusahaan atau kesepakatan antara karyawan dengan perusahaan serta rata-rata upah karyawan di masa lalu, Standar efisiensi ditetapkan dengan melihat kinerja aktual dari seorang pekerja. Metode penelitian yang digunakan dalam penelitian ini adalah deskriptif dengan pendekatan kuantitatif. Data penelitian yang digunakan dalam penelitian ini adalah data sekunder. Sumber data yang tidak langsung memberikan data kepada pengumpul data, Selisih biaya tenaga kerja langsung yang terjadi di PT Masaiki adalah bersifat menguntungkan. Walaupun selisih menguntungkan dalam pengendalian biaya tenaga kerja langsung belum tentu merupakan selisih menguntungkan yang optimal, tetapi apabila perusahaan menggunakan biaya standar dengan analisis selisih secara kontinyu/terus menerus dalam pengendalian biaya tenaga kerja langsung maka biaya tenaga kerja langsung yang harus dikeluarkan perusahaan akan rendah dan biaya yang rendah akan menaikkan laba sehinggga laba yang optimal akan dicapai perusahaan.
\end{abstract}

Kata kunci: Tenaga Kerja Langsung, Pengendalian, Biaya Standar 


\section{Pendahuluan}

Suatu institusi atau badan usaha tidak akan pernah lepas dari persaingan dalam usahanya untuk memenuhi hasil yang diinginkan. Untuk menghadapi persaingan tersebut, suatu organisasi atau badan usaha harus menentukan strategi agar mampu menghadapi persaingan dengan badan usaha lain.

Untuk tetap menjaga keberadaan badan usaha di kompetisi dan demi kesuksesan bisnis, maka kelompok manajemen harus jeli memandang hal-hal yang bisa menggoyahkan perusahaan baik dari aspek dari dalam maupun aspek dari luar maupun ekstern badan usaha. Faktor dari dalam meliputi kualitas dan kuantitas tenaga kerja, modal dan fasilitas perusahaan, kualitas dan kuantitas produk, usaha pemasaran dan lain sebagainya. Sedangkan faktor dari luar antara lain minat konsumen (trend pasar), situasi politik, fluktuasi harga (termasuk akibat inflasi) dan lain sebagainya.

Pekerja adalah aspek yang sangat berguna di sebuah badan usaha sebab dengan adanya pekerja proses badan usaha dapat berlangsung. Untuk mendapatkan pekerja yang sesuai, maka pihak manajemen butuh melaksanakan pembinaan dan pengendalian yang baik.

Biaya pekerja adalah bagian terpenting dari banyaknya output dari anggaran badan usaha. Jumlah total biaya pekerja merupakan jumlah yang besar atau tidak sedikit. Sehingga perlu disusun dan di kontrol agar biaya pekerja efektif dan efisien.

Penanggulangan anggaran dari tenaga kerja ini dapat dilaksanakan dengan bermacam cara. Salah satu cara dengan menganalisis atau membandingkan antara biaya maupun waktu yang distandarkan dengan biaya maupun waktu yang sebenarnya terjadi. Apakah terjadi selisih atau tidak, bila terdapat selisih perlu diteliti apakah selisih itu menguntungkan atau selisih rugi.

Jumlah total biaya pekerja merupakan jumlah yang besar, sehingga perlu di susun dan di kontrol supaya biaya pekerja efektif dan efisien sehingga tidak terjadi selisih. Badan usaha Sepatu Masaiki beroperasi di home industri sepatu. Badan Usaha Sepatu Masaiki kegiatan produksinya menghadapi kemungkinan terjadi selisih di anggaran dengan biaya aktualnya. Observasi ini mempelajari mengenai selisih yang terjadi antara anggaran pengeluaran yang telah disusun dengan realisasi biaya aktualnya yang terjadi dan hal - hal penyebab adanya selisih tersebut selama 6 bulan periode Januari - Juni pada tahun 2013.

Dari hasil analisis tersebut, diharapkan untuk periode - periode berikutnya pengendalian dan penetapan biaya pekerja dapat lebih optimal guna perkembangan perusahaan dan kesejahteraan para karyawan.

Artikel ini juga disadur dari beberapa jurnal diantaranya : 
1. ANALISIS BIAYA STANDAR SEBAGAI ALAT PENGENDALIAN BIAYA PRODUKSI (Studi pada PT Petrokimia Kayaku Gresik Periode Tahun 2013) : (Husnah, 2015) di Jurnal Administrasi Bisnis. Jurnal ini menerangkan serta menganalisa penerapan biaya yang dianggarkan sebagai alat kontrol anggaran produksi di PT Petrokimia Kayaku Gresik dengan periode penelitian tahun 2013.

2. ANALISIS EFISIENSI BIAYA TENAGA KERJA LANGSUNG PADA PT. ADINATA SUNGGUMINASA (Rustam et al., 2019) pada Jurnal Riset Perpajakan, Jurnal ini yaitu memahami efisien anggaran pekerja langsung yang dilaksanakan PT. Adinata.

Berikut ini beberapa definisi pendapat pakar :

Biaya adalah suatu pengabdian yang asalnya yaitu sumber ekonomi yang bisa diukur didalam satuan uang yang sudah dipakai atau peluang akan terpakai untuk maksud tertentu ((Widilestariningtyas, O., Firdaus, D. W., Anggadini, 2012).

Biaya yaitu uang tunai atau nilai yang sama dengan uang tunai yang akan diberikan sehingga dapat produk atau jasa yang menyediakan faedah periode sekarang atau di periode yang akan datang untuk badan usaha (Hansen, D. R., Maryanne, 2009).

Biaya yang dianggarkan / Standar adalah pengeluaran yang akan dilaksanakan dimuka yang membuat jumlah output yang semestinya dipakai untuk memproduksi suatu unit barang atau untuk mendanai beberapa proses, dibawah asumsi kondisi ekonomi, efisiensi dan faktorfaktor lain tertentu ( M u l y a di , 2005 ).

Biaya yang dianggarkan / standar adalah pengeluaran yang akan dilaksanakan sebelum menghasilkan suatu satuan atau sejumlah produk tertentu pada satu periode tertentu ( Carter, W. K., 2009 )

Pengendalian dipakai dalam hal sesuai dengan tujuan strategis (Anthony, R. N., Govindarajan, 2002).

Pengendalian pengeluaran produksi dilakukan hanya untuk menjaga dan meningkatkan efisiensi dari pengeluaran produksi. Pengendalian pengeluaran yang efektif bergantung pada apresiasi manajemen atas suatu proses yang memicu pengeluaran dan atas suatu motivasi karyawan yang akan melayani kegiatan tersebut (Carter, W. K., 2009).

Biaya pekerja langsung adalah pengeluaran yang menjadi output untuk menggaji pegawai yang berperan serentak (Rudianto, 2009).

Biaya pekerja langsung merupakan timbal balik yang akan diberikan kepada para pegawai pabrik yang mendapatkan faedah serta dapat dikenal atau diikuti alirannya pada barang tertentu yang merupakan output badan usaha (Supriyono, 2000). 


\section{Metode Penelitian}

Metode observasi yang digunakan dalam penulisan ini adalah deskriptif dengan pendekatan kuantitatif.

Data observasi yang digunakan dalam penulisan ini adalah informasi yang sudah ada sebelumnya. Sumber data yang secara kebetulan menyerahkan informasi kepada penampung informasi, melalui perantara orang lain atau perantara arsip. Data sekunder yaitu input bersumber dari informasi yang kebetulan dari basis informasi antara lain dipresentasikan dalam bentuk informasi - informasi, tabulasi - tabulasi, grafik - grafik, atau perihal tema observasi. Data yang dipakai dari topik yang akan dibahas, hasil di internet mengenai artikel, jurnal, dan laporan hasil dari pelaksanaan proses yang dapat digunakan oleh penulis sebagai bahan perbandingan dengan penulisan yang dilaksanakan. (Sugiyono, 2016).

Berikut ini Rancangan Penulisan yang digunakan :

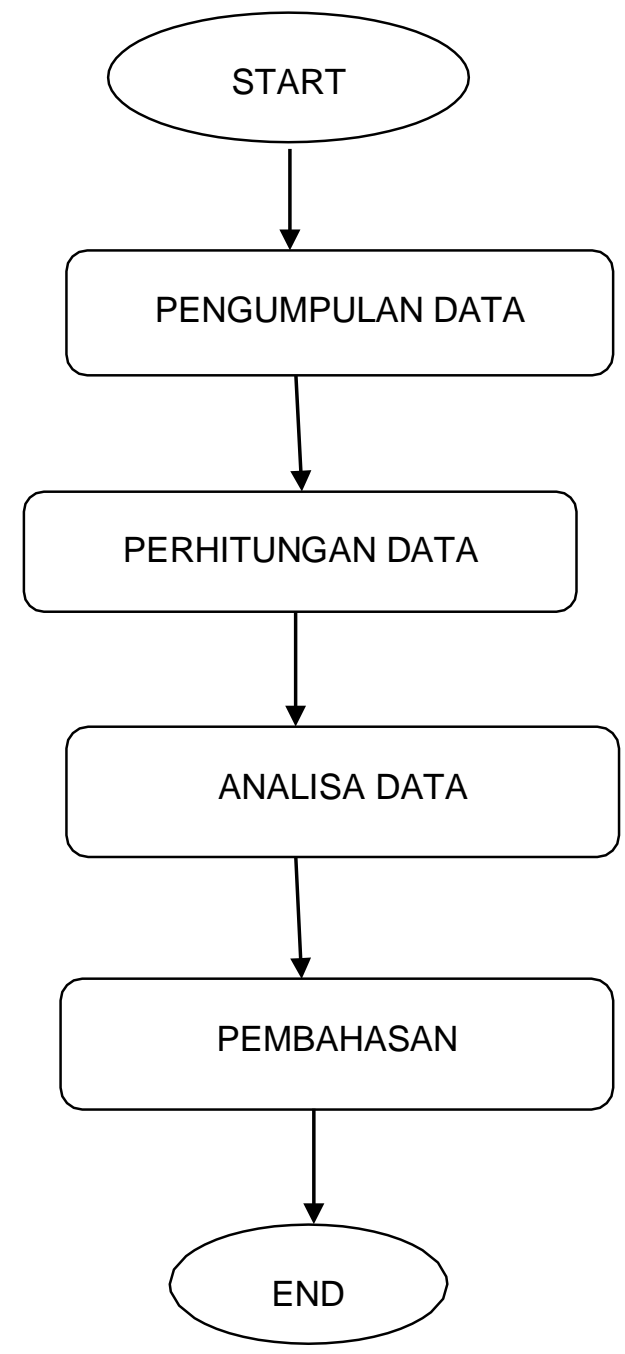

Sumber : Hasil Penelitian (2013)

Gambar 1. Rancangan Penelitian 


\section{Hasil dan Pembahasan}

\subsection{Metode Analisa}

Metode analisa yang dipakai dalam observasi ini adalah analisis selisih biaya yang dianggarkan / standar. Selisih dikatakan memberikan keuntungan (favorable) jika anggaran sesungguhnya lebih kecil dari anggaran yang ada, sedangkan selisih dikatakan rugi (unfavorable) jika anggaran sesungguhnya lebih besar dari anggaran yang ada. Berikut rumus untuk mencari selisih biaya yang dianggarkan biaya pekerja langsung :

Tabel 1. Rumus Selisih Pengeluaran Yang Dianggarkan Biaya Pekerja Langsung

\begin{tabular}{lc}
\hline \multicolumn{1}{c}{ Perhitungan } & Rumus \\
\hline Perhitungan varians tarif upah langsung & STU $=($ TUSt - TUS $) \times$ JKSt \\
\hline Perhitungan varians efisiensi upah langsung & SEUL $=(\mathrm{JKSt}-\mathrm{JKS}) \times$ TUSt \\
\hline Perhitungan varians tarif $/$ efisiensi upah langsung & STEUL $=(\mathrm{JKSt}-\mathrm{JKS}) \times(\mathrm{TUSt}-\mathrm{TUS})$ \\
\hline
\end{tabular}

Sumber: Hasil Penelitian (2013)

\subsection{Perhitungan Biaya pekerja Langsung yang dianggarkan}

Pada Tahun 2012, PT Masaiki menggunakan biaya pekerja aktual sebesar Rp2.039.625.000 (dalam periode 6 bulan). Biaya tersebut lalu dipakai sebagai biaya yang dianggarkan pada Tahun 2013.

Penjelasan kalkulasi pengeluaran pekerja langsung sebagai berikut :

1. Jam Kerja per pekerja langsung ditetapkan berdasarkan taksiran yang wajar, yang didasarkan pada kemahiran dan pengetahuan operasi produksi dan produk.

2. Jumlah jam kerja didapat dari perkalian antara jumlah pekerja langsung dengan jam kerja per pekerja langsung.

3. Tarif upah per hari ditetapkan berdasarkan kesepakatan antara pekerja dan badan usaha.

4. Biaya pekerja langsung badan usaha Sepatu Masaiki didapat dari jumlah jam kerja pekerja langsung dikalikan dengan tarif upah per hari.

Dari kalkulasi pengeluaran pekerja langsung tersebut didapat informasi sebagai berikut:

Tabel 2. Biaya Pekerja Yang Dianggarkan Badan Usaha Periode Produksi 2013

\begin{tabular}{cccccc}
\hline \multirow{2}{*}{ Bulan } & $\begin{array}{c}\text { Jml } \\
\text { Tkl }\end{array}$ & $\begin{array}{c}\text { Jam Kerja } \\
\text { Per Tkl }\end{array}$ & $\begin{array}{c}\text { Jml Jam } \\
\text { Kerja }\end{array}$ & $\begin{array}{c}\text { Tarif Upah } \\
\text { Per Hari }\end{array}$ & Total Biaya \\
\hline & & & $\mathbf{( 1 \times x )}$ & & $(\mathbf{3} \times \mathbf{4})$ \\
\hline Januari & $(1)$ & $(2)$ & $(3)$ & $(4)$ & $(5)$ \\
\hline Februari & 25 & 192.29 & 4,807 & 70,000 & $336,507,500$ \\
\hline Maret & 25 & 190.20 & 4,755 & 70,000 & $332,850,000$ \\
\hline
\end{tabular}


Analisis Biaya Standar Sebagai Alat Pengendalian Biaya Tenaga Kerja Langsung pada PT Masaiki Jakarta

\begin{tabular}{cccccc}
\hline April & 25 & 191.28 & 4,782 & 70,000 & $334,740,000$ \\
\hline Mei & 25 & 192.27 & 4,807 & 70,000 & $336,472,500$ \\
\hline Juni & 25 & 210.19 & 5,255 & 70,000 & $367,832,500$ \\
\hline Total & & & & $2,039,625,000$ \\
\hline
\end{tabular}

Sumber: Hasil Penelitian (2013)

\subsection{Perhitungan Biaya Pekerja Sesungguhnya (Aktual)}

Kalkulasi anggaran pekerja sesungguhnya (Aktual) atau populasi didapat setelah produksi sepatu tersebut selesai diproduksi oleh badan usaha. Perhitungan kembali biaya pekerja aktual yang telah dipakai dapat memperlihatkan besarnya pengeluaran pekerja yang telah dipakai, apakah pengeluaran pekerja langsung tersebut sudah sesuai dengan yang dianggarkan / standar atau melebihi dari yang dianggarkan / standar yang telah ditentukan. Dari perhitungan biaya pekerja langsung tersebut didapat informasi sebagai berikut:

Tabel 3. Biaya Pekerja Sesungguhnya (Aktual) Badan Usaha Periode Produksi 2013

\begin{tabular}{cccccc}
\hline \multirow{2}{*}{ Bulan } & $\begin{array}{c}\text { Jml } \\
\text { Tkl }\end{array}$ & $\begin{array}{c}\text { Jam Kerja } \\
\text { Per Tkl }\end{array}$ & $\begin{array}{c}\text { Jml Jam } \\
\text { Kerja }\end{array}$ & $\begin{array}{c}\text { Tarif Upah } \\
\text { Per Hari }\end{array}$ & Total Biaya \\
\hline & & & $(1 \times 2)$ & & $(3 \times 4)$ \\
\hline Januari & 25 & 204.20 & $5,105.00$ & 70,000 & $357,350,000$ \\
\hline Februari & 25 & 203.45 & $5,086.25$ & 70,000 & $356,037,500$ \\
\hline Maret & 25 & 192.28 & $4,807.00$ & 70,000 & $336,490,000$ \\
\hline April & 25 & 191.27 & $4,781.75$ & 70,000 & $334,722,500$ \\
\hline Mei & 25 & 191.17 & $4,779.25$ & 70,000 & $334,547,500$ \\
\hline Juni & 25 & 200.16 & $5,004.00$ & 70,000 & $350,280,000$ \\
\hline Total & & & & & $2,069,427,500$ \\
\hline
\end{tabular}

Sumber: Hasil Penelitian (2013)

\subsection{Pengendalian Biaya Pekerja Badan Usaha Memakai Pengeluaran Yang Dianggarkan / Standar Dan Pengeluaran Sesungguhnya (Aktual)}

Output dari analisa perhitungan biaya pekerja langsung tersebut diketahui bahwa pengeluaran pekerja langsung yang aktual berjumlah $\mathrm{Rp}$ 2.069.427.500. Dimana menunjukkan biaya pekerja yang dianggarkan tidak selalu sama dengan pengeluran pekerja aktual badan usaha. 
Tabel 4. Varians Dari Total Pengeluaran Yang Dianggarkan dan Total Pengeluran Sesungguhnya

\begin{tabular}{cccc}
\hline Bulan & Total Biaya Standar & Total Biaya Aktual & Selisih \\
\hline Januari & $336,507,500$ & $357,350,000$ & $(20,842,500)$ \\
\hline Feb & $332,850,000$ & $356,037,500$ & $(23,187,500)$ \\
\hline Mar & $331,222,500$ & $336,490,000$ & $(5,267,500)$ \\
\hline Apr & $334,740,000$ & $334,722,500$ & 17,500 \\
\hline Mei & $336,472,500$ & $334,547,500$ & $1,925,000$ \\
\hline Juni & $367,832,500$ & $350,280,000$ & $17,552,500$ \\
\hline Jumlah & $2,039,625,000$ & $2,069,427,500$ & $(29,802,500)$ \\
\hline
\end{tabular}

Sumber: Hasil Penelitian (2013)

Tabel 5. Perhitungan Selisih Biaya Pekerja Langsung Metode Tiga Selisih Tarif Upah

\begin{tabular}{|c|c|}
\hline Bulan & Selisih \\
\hline Januari & $(\operatorname{Rp} 70.000-\operatorname{Rp} 70.000) \times 4.807,25=\operatorname{Rp} 0$ \\
\hline Februari & $(\operatorname{Rp} 70.000-R p 70.000) \times 4.755$ \\
\hline Maret & $(\operatorname{Rp} 70.000-R p 70.000) \times 4.729,25=R p 0$ \\
\hline April & $(\operatorname{Rp} 70.000-\operatorname{Rp} 70.000) \times 4.782$ \\
\hline Mei & $(\operatorname{Rp} 70.000-R p 70.000) \times 4.806,75=\operatorname{Rp} 0$ \\
\hline Juni & $(\operatorname{Rp} 70.000-\operatorname{Rp} 70.000) \times 5.254,75=R p 0$ \\
\hline
\end{tabular}

Sumber: Hasil Penelitian (2013)

Tabel 6. Selisih Efisiensi Upah

\begin{tabular}{|c|c|c|}
\hline Bulan & Selisih & \\
\hline Januari & $(4.807,25-5.105) \times \operatorname{Rp} 70.000$ & $=\operatorname{Rp}(20.842 .500)$ \\
\hline Februari & $(4.755-5.086,25) \times \operatorname{Rp} 70.000$ & $=\operatorname{Rp}(23.187 .500)$ \\
\hline Maret & $(4.729,25-4.807) \times \operatorname{Rp} 70.000$ & $=\operatorname{Rp}(5.442 .500)$ \\
\hline April & $(4.782-4.781,75) \times \operatorname{Rp} 70.000$ & $=\mathrm{Rp}$ \\
\hline Mei & $(4.806,75-4.779,25) \times \operatorname{Rp} 70.000$ & $=\mathrm{Rp} \quad 1.925 .000$ \\
\hline Juni & $(5.254,75-5.004) \times \operatorname{Rp} 70.000$ & $=\operatorname{Rp} 17.552 .500$ \\
\hline
\end{tabular}

Sumber: Hasil Penelitian (2013) 
Tabel 7. Selisih Tarif / Efisiensi Upah

\begin{tabular}{ccc}
\hline Bulan & Selisih & \\
\hline Januari & $(4.807,25-5.105) \times(\operatorname{Rp~70.000-Rp~70.000)~}$ & $=\mathrm{Rp} \mathrm{0}$ \\
\hline Februari & $(4.755-5.086,25) \times(\operatorname{Rp~70.000-Rp~70.000)~}$ & $=\mathrm{Rp} \mathrm{0}$ \\
\hline Maret & $(4.729,25-4.807) \times(\mathrm{Rp} \mathrm{70.000-Rp} \mathrm{70.000)}$ & $=\mathrm{Rp} \mathrm{0}$ \\
\hline April & $(4.782-4.781,75) \times(\mathrm{Rp} \mathrm{70.000-Rp} \mathrm{70.000)}$ & $=\mathrm{Rp} \mathrm{0}$ \\
\hline Mei & $(4.806,75-4.779,25) \times(\operatorname{Rp~70.000-Rp~70.000)~}$ & $=\mathrm{Rp} \mathrm{0}$ \\
\hline Juni & $(5.254,75-5.004) \times(\operatorname{Rp~70.000-Rp~70.000)~}$ & $=\mathrm{Rp} \mathrm{0}$
\end{tabular}

Sumber: Hasil Penelitian (2013)

Dari perhitungan diatas bahwa selisih tarif upah dan selisih tarif atau efisiensi pada periode Januari - Juni tidak berpengaruh terhadap pengeluaran badan usaha. Untuk efisiensi upah yang berkaitan dengan waktu yang dibutuhkan untuk memproduksi produk tersebut pada periode Januari - Maret mempengaruhi pengeluaran Perusahaan dengan terjadinya selisih rugi sebesar Rp 49.472.500, sedangkan untuk efisiensi upah dari bulan April sampai bulan Juni didapatkan selisih yang menguntungkan sebesar Rp 19.495.000.

Tabel 8. Analisis Perbandingan Biaya Tenaga Kerja Keseluruhan

\begin{tabular}{cccc}
\hline Bulan & $\begin{array}{c}\text { Biaya tenaga kerja } \\
\text { langsung standar }\end{array}$ & $\begin{array}{c}\text { Biaya tenaga kerja } \\
\text { langsung sesungguhnya }\end{array}$ & Selisih (R) \\
\hline Januari & $\mathrm{Rp} \mathrm{336.507.500}$ & $\mathrm{Rp} \mathrm{357.350.000}$ & $\mathrm{Rp} \mathrm{20.842.500}$ \\
\hline Februari & $\mathrm{Rp} \mathrm{332.850.000}$ & $\mathrm{Rp} \mathrm{356.037.500}$ & $\mathrm{Rp} \mathrm{23.187.500}$ \\
\hline Maret & $\mathrm{Rp} \mathrm{331,222,500}$ & $\mathrm{Rp} \mathrm{336,490,000}$ & $\mathrm{Rp} \mathrm{5,267,500}$ \\
\hline
\end{tabular}

Sumber: Hasil Penelitian (2013)

Berarti perbandingan biaya pekerja langsung badan usaha ini pada periode Januari Maret di didapat selisih rugi/penyimpangan dari standar.

Selisih rugi/penyimpangan dari standar ini disebabkan karena anggaran pekerja langsung yang dianggarkan badan usaha lebih sedikit dari anggaran pekerja langsung sesungguhnya.

Faktor yang menyebabkan biaya pekerja langsung standar badan usaha lebih sedikit dari anggaran pekerja langsung sesungguhnya/actual badan usaha adalah jumlah jam kerja yang digunakan selama proses pembuatan lebih besar dari yang ditetapkan, hal ini dikarenakan badan usaha harus memproduksi diatas kapasitas normal yang ditetapkan badan usaha sebelumnya karena adanya pesanan dari pelanggan. 
Tabel 9. Perhitungan selisih hasil upah langsung karena adanya penambahan produksi

\begin{tabular}{cccc}
\hline Bulan & Hasil Standar $\mathbf{x}$ TUst & Hasil Aktual x TUst & Selisih (L) \\
\hline Januari & $1200 \times \mathrm{Rp} 70.000=\mathrm{Rp}$ & $1500 \times \mathrm{Rp} \mathrm{70.000}=\mathrm{Rp}$ & $\mathrm{Rp} 21.000$ \\
& 84.000 & 105.000 & \\
\hline Februari & $1200 \times \mathrm{Rp} 70.000=\mathrm{Rp}$ & $1650 \times \mathrm{Rp} 70.000=$ & $\mathrm{Rp}$ \\
& 84.000 .000 & $\underline{\mathrm{Rp}} 115.500 .000$ & 31.500 .000 \\
\hline Maret & $1200 \times \mathrm{Rp} \mathrm{70.000}=\mathrm{Rp}$ & $1300 \times \mathrm{Rp} 70.000=$ & $\mathrm{Rp}$ \\
& 84.000 .000 & $\mathrm{Rp} 91.000 .000$ & 7.000 .000 \\
\hline
\end{tabular}

Sumber: Hasil Penelitian (2013)

Berdasarkan perhitungan varians hasil upah langsung dapat dikatakan walaupun biaya pekerja langsung yang diangggarkan lebih kecil dari biaya pekerja langsung aktual tetapi badan usaha tetap dalam keadaan menguntungkan karena penambahan jam kerja dapat ditutupi dengan adanya keuntungan yang didapat badan usaha karena badan usaha dapat memproduksi diatas kapasitas produksi normal/yang ditetapkan untuk memenuhi pesanan pelanggan.

Perbandingan biaya pekerja langsung yang dikeluarkan karena penambahan jam kerja dengan selisih upah langsung yang didapat karena adanya penambahan jam kerja sebagai berikut :

Tabel 10. Perhitungan selisih hasil upah langsung karena adanya penambahan produksi

\begin{tabular}{|c|c|c|c|}
\hline Bulan & $\begin{array}{l}\text { Selisih Biaya Tenaga } \\
\text { Kerja Langsung } \\
\text { Sebelum Penambahan } \\
\text { Jam Kerja }\end{array}$ & $\begin{array}{c}\text { Selisih Biaya Tenaga } \\
\text { Kerja Langsung } \\
\text { Setelah Penambahan } \\
\text { Jam Kerja }\end{array}$ & Selisih Total (L) \\
\hline Januari & $\mathrm{Rp} 20.842 .500$ & Rp 21.000.000 & 157.500 \\
\hline Februari & Rp 23.187.500 & Rp 31.500 .000 & $\mathrm{Rp} \quad 8.312 .500$ \\
\hline Maret & Rp $5,267,500$ & Rp 7.000 .000 & Rp 1.732 .500 \\
\hline
\end{tabular}

Sumber: Hasil Penelitian (2013)

Dari analisa diatas dapat dikatakan bahwa manajer produksi telah mengambil keputusan yang tepat dalam mengendalikan dan menetapkan biaya pekerja langsung badan usaha. Hal itu dapat dilihat dengan adanya selisih total yang menguntungkan bagi perusahaan.

Perbandingan biaya pekerja langsung badan usaha dari bulan April sampai Juni didapat selisih yang menguntungkan sebagai berikut: 
Tabel 11. Perbandingan Pengeluaran Pekerja Langsung

\begin{tabular}{ccccc}
\hline Bulan & $\begin{array}{c}\text { Biaya Tenaga } \\
\text { Kerja Langsung } \\
\text { Standar }\end{array}$ & $\begin{array}{c}\text { Biaya Tenaga } \\
\text { Kerja Langsung } \\
\text { Sesungguhnya }\end{array}$ & Selisih (L) \\
\hline April & $R p 334,740,000$ & Rp 334,722,500 & Rp 17.500 \\
\hline Mei & $R p 336,472,500$ & $R p 334,547,500$ & $R p ~ 1,925,000$ \\
\hline Juni & $R p 367,832,500$ & $R p 350,280,000$ & $R p ~ 17,552,500$ \\
\hline
\end{tabular}

Sumber: Hasil Penelitian (2013)

Dengan terjadinya selisih yang menguntungkan dari bulan April sampai bulan Juni maka manajer produksi menyimpulkan bahwa ini bukan sebagai masalah.

Walaupun varians menguntungkan dalam mengendalikan biaya pekerja langsung belum tentu merupakan varians menguntungkan yang maksimal, namun apabila badan usaha menggunakan biaya yang dianggarkan dengan analisis selisih secara terus - menerus dalam mengendalikan biaya pekerja langsung maka biaya pekerja langsung yang harus digunakan badan usaha akan kecil dan biaya yang kecil akan menaikkan keuntungan sehingga keuntungan yang maksimal akan didapat badan usaha.

\section{Kesimpulan}

Biaya pekerja adalah bagian terpenting dari banyaknya pengeluaran yang harus digunakan oleh badan usaha. Jumlah total biaya pekerja merupakan jumlah yang besar atau tidak sedikit. Sehingga perlu direncanakan dan dikendalikan agar biaya pekerja efektif dan efisien.

Jumlah total biaya pekerja merupakan jumlah yang besar, sehingga perlu direncanakan dan dikendalikan agar biaya pekerja efektif dan efisien sehingga tidak terjadi selisih. Badan Usaha Sepatu Masaiki beroperasi di home industri sepatu. Badan Usaha Sepatu Masaiki ini dalam proses produksinya menghadapi kemungkinan terjadinya selisih antara biaya yang telah dianggarkan/ standar dengan biaya aktualnya. Observasi ini mempelajari mengenai selisih yang terjadi antara anggaran biaya yang telah ditentukan dengan realisasi biaya aktualnya yang terjadi. Dan hal - hal penyebab adanya selisih tersebut selama 6 bulan periode Januari - Juni pada tahun 2013.

Berdasarkan hasil analisis yang telah Penulis kemukakan diatas, maka dapat ditarik suatu kesimpulan besarnya varians biaya pekerja langsung yang terjadi dalam 6 bulan sebagai berikut : 
Tabel 10. Perhitungan selisih hasil upah langsung karena adanya penambahan produksi

\begin{tabular}{ccccc}
\hline Bulan & $\begin{array}{c}\text { Selisih Biaya Tenaga } \\
\text { Kerja Langsung } \\
\text { Sebelum Penambahan } \\
\text { Jam Kerja }\end{array}$ & $\begin{array}{c}\text { Selisih Biaya Tenaga } \\
\text { Kerja Langsung } \\
\text { Setelah Penambahan } \\
\text { Jam Kerja }\end{array}$ & Selisih Total (L) \\
\hline Januari & $\mathrm{Rp} \mathrm{20.842.500}$ & $\mathrm{Rp} 21.000 .000$ & $\mathrm{Rp}$ & 157.500 \\
\hline Februari & $\mathrm{Rp} \mathrm{23.187.500}$ & $\mathrm{Rp} 31.500 .000$ & $\mathrm{Rp}$ & 8.312 .500 \\
\hline Maret & $\mathrm{Rp} 5,267,500$ & $\mathrm{Rp} 7.000 .000$ & $\mathrm{Rp}$ & 1.732 .500 \\
\hline
\end{tabular}

Tabel 11. Perbandingan Pengeluaran Pekerja Langsung

\begin{tabular}{ccccc}
\hline Bulan & $\begin{array}{c}\text { Biaya Tenaga } \\
\text { Kerja Langsung } \\
\text { Standar }\end{array}$ & $\begin{array}{c}\text { Biaya Tenaga } \\
\text { Kerja Langsung } \\
\text { Sesungguhnya }\end{array}$ & Selisih (L) & \\
\hline April & Rp 334,740,000 & Rp 334,722,500 & Rp 17.500 \\
\hline Mei & $R p 336,472,500$ & $R p 334,547,500$ & $R p ~ 1,925,000$ \\
\hline Juni & $R p 367,832,500$ & $R p 350,280,000$ & $R p ~ 17,552,500$ \\
\hline
\end{tabular}

Dengan terjadinya selisih yang menguntungkan pada perusahaan belum tentu selisih yang menguntungkan tersebut adalah selisih menguntungkan yang maksimal, tetapi dengan mempergunakan biaya standar analisis selisih secara terus menerus yang dilakukan perusahaan dalam mengendalikan biaya pekerja langsung sehingga akan menurunkan biaya pekerja langsung yang harus digunakan badan usaha pada tingkat yang lebih rendah, dengan biaya yang rendah maka keuntungan yang maksimal akan diperoleh badan usaha.

\section{Daftar Pustaka}

Anthony, R. N., Govindarajan, V. (2002). Management Control System. Salemba Empat.

Carter, W. K. (2009). Cost Accounting. Salemba Empat.

Hansen, D. R., Maryanne, M. M. (2009). Akuntansi Manajemen. Erlangga.

Husnah, Z. (2015). ANALISIS BIAYA STANDAR SEBAGAI ALAT PENGENDALIAN BIAYA

PRODUKSI (Studi pada PT Petrokimia Kayaku Gresik Periode Tahun 2013). Jurnal Administrasi

Bisnis S1 Universitas Brawijaya, 27(1), 86324.

Mulyadi. (2005). Akuntansi Biaya. STIE YKPN.

Rudianto. (2009). Penganggaran. Salemba Empat.

Rustam, A., Arifwangsa, A., \& Adiningrat, A. (2019). Analisis Efisiensi Biaya Tenaga Kerja Langsung

Pada Pt. Adinata Sungguminasa. Amnesty: Jurnal Riset Perpajakan, 1(1), 15-20.

https://doi.org/10.26618/jrp.v2i1.2531

Sugiyono. (2016). Metode Penelitian Dan Pengembangan (Research and Development/R\&D).

Alfabeta.

Copyright $\odot 2021$ Jurnal JIFORTY 2(1): 23-34 (Juni 2021) 
Analisis Biaya Standar Sebagai Alat Pengendalian Biaya Tenaga Kerja Langsung pada PT Masaiki Jakarta Supriyono. (2000). Akuntansi Biaya: Perencanaan dan Pengendalian Biaya serta Pembuatan Keputusan. BPFE.

Widilestariningtyas, O., Firdaus, D. W., Anggadini, S. D. (2012). Akuntansi Biaya. Graha Ilmu. 